\title{
Bilateral fractures in a shoulder dystocia delivery
}

\author{
Timothy Shao Ern Tan, Abida Mohamed, Sandeep Dharmaraj
}

Department of Neonatology, Lancashire Teaching Hospitals NHS Foundation Trust, Preston, UK

\section{Correspondence to} Dr Timothy Shao Ern Tan, timothy.tan.shao.ern@doctors. org.uk

Accepted 20 October 2016

\section{DESCRIPTION}

A male neonate weighing $4170 \mathrm{~g}$ (99th centile) was born to a non-diabetic primigravid woman by difficult vaginal delivery at 37 weeks gestation due to right shoulder dystocia. The labour was induced and Neville Barnes forceps were employed for successful delivery. Apart from maternal obesity (body mass index of $36 \mathrm{~kg} / \mathrm{m}^{2}$ ), no other risk factors for fetal macrosomia or shoulder dystocia were noted. After birth, absent right shoulder movement with asymmetrical Moro reflex was noted, raising the possibility of right clavicular fracture with possible brachial plexus injury (BPI). Although left arm mobility was reduced, neurology was normal. Both elbows and wrists were flexed with symmetrical grasp reflex. A chest radiograph was performed, confirming displaced fractures of his right clavicle and left humerus (figure 1). Examination findings at 48 hours were unchanged, and there were no signs of Horner's syndrome or respiratory distress indicating phrenic nerve injury. It was difficult to elicit upper limb reflexes possibly due to discomfort. He made a good recovery with immobilisation, splinting, physiotherapy and regular orthopaedic reviews (figure 2).

Owing to the relative absence of maternal risk factors and an estimated fetal weight of $3700 \mathrm{~g}$, it was difficult to predict the occurrence of shoulder dystocia. Moreover, the last antenatal scan before delivery showed the presentation to be cephalic and the infant's head to be deeply engaged. As such, a decision was made for induction of labour and there was no consideration to opt for elective caesarean section (ELCS) in the antenatal period as the pregnancy was deemed as 'low risk'.

Clavicular and/or humeral fractures are welldescribed sequelae of shoulder dystocia which may be associated with BPI. ${ }^{1}$ Furthermore, the use of forceps during delivery can also contribute to BPI. However, most cases of BPI will eventually resolve, with fewer than $10 \%$ left with a permanent neurological disability. ${ }^{2}$ In the absence of specific signs and symptoms, a humeral fracture with possible associated radial nerve palsy could have been missed, ${ }^{3}$ especially when right-sided symptoms may mask any left-sided injuries as in our case. Hence, this highlights the importance of a high suspicion index towards bilateral fractures in shoulder dystocia deliveries, especially where there is the use of instrumentation and clinical evidence of reduced or absent limb movements bilaterally. This warrants early imaging of both clavicles including the humerii where indicated to exclude harmful fractures. Furthermore, a thorough neurological and musculoskeletal (assessing for crepitus and bony deformity) examination of the newborn should be undertaken at birth and at 48 hours of age to

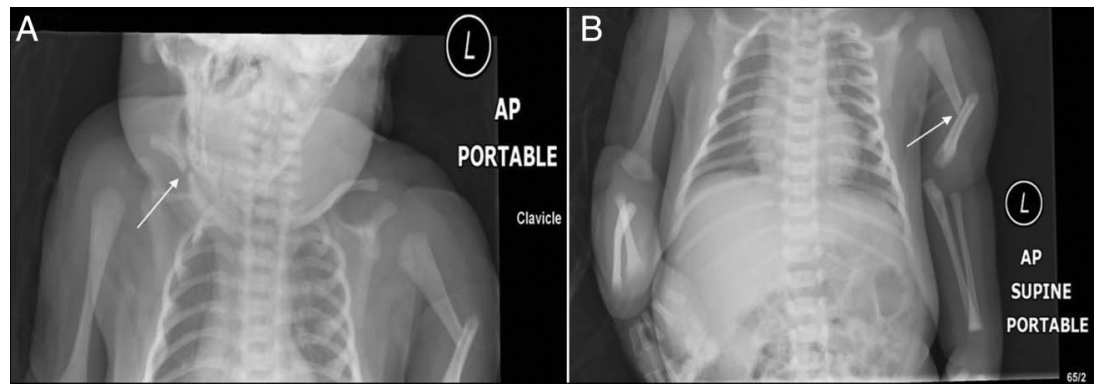

Figure 1 Chest radiograph demonstrating displaced right clavicular $(A)$ and left humeral fractures (B) at birth (shown with arrows).

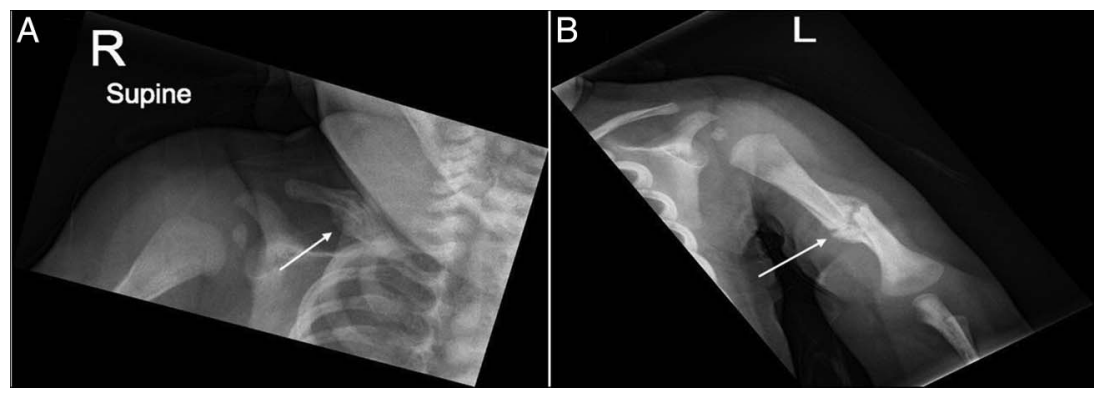

Figure 2 Post-reduction chest radiograph 1 month later demonstrating healing right clavicular fracture (A) and left humeral fracture (B) with callus formation (shown with arrows). 
ascertain the extent of neurological injury and to ensure early intervention. Although the occurrence of bilateral fractures in shoulder dystocia is uncommon, especially in low-risk pregnan-

\section{Learning points}

- Bilateral upper limb fractures involving different bones are uncommon complications of shoulder dystocia, and can be difficult to recognise due to non-specific signs or symptoms which may also represent neurological injury.

- In infants born with shoulder dystocia during delivery and are found to have reduced or absent limb movements, bilateral fractures with neurological injury should be suspected.

- Repeat clinical assessments and early radiological imaging are essential to confirm fractures and determine any neurological damage so as to ensure early appropriate intervention. cies, prompt detection and treatment can aid in good recovery. Fortunately for our case, his BPI fully resolved by 3 months of age with no residual neurological deficit.

Contributors TSET prepared and submitted the manuscript. SD (consultant in charge of the patient's care) and AM identified the images and reviewed the manuscript. All authors were involved in the care of the patient and approved the final manuscript.

Competing interests None declared.

Patient consent Obtained.

Provenance and peer review Not commissioned; externally peer reviewed.

\section{REFERENCES}

1 Politi S, d'emidio L, Cignini P, et al. Shoulder dystocia: an evidence-based approach. J Prenat Med 2010;4:35-42.

2 Royal College of Obstetricians and Gynaecologists (RCOG). Shoulder dystocia. Green-top Guideline No. 42. 2nd edn. 2012. https://www.rcog.org.uk/globalassets/ documents/guidelines/gtg_42.pdf (accessed 17 Oct 2016).

3 Shao YC, Harwood P, Grotz MR, et al. Radial nerve palsy associated with fractures of the shaft of the humerus: a systematic review. J Bone Joint Surg $\mathrm{Br}$ 2005;87:1647-52.

Copyright 2016 BMJ Publishing Group. All rights reserved. For permission to reuse any of this content visit http://group.bmj.com/group/rights-licensing/permissions.

BMJ Case Report Fellows may re-use this article for personal use and teaching without any further permission.

Become a Fellow of BMJ Case Reports today and you can:

- Submit as many cases as you like

- Enjoy fast sympathetic peer review and rapid publication of accepted articles

- Access all the published articles

- Re-use any of the published material for personal use and teaching without further permission

For information on Institutional Fellowships contact consortiasales@bmjgroup.com

Visit casereports.bmj.com for more articles like this and to become a Fellow 